\title{
Supply Shocks and Gender Bias in Child Health Investments: Evidence from the ICDS Programme in India *
}

\author{
Abhishek Chakravarty ${ }^{\dagger}$
}

March 16, 2009

\begin{abstract}
This paper examines whether a permanent increase in the supply of immunisations reduces or intensifies gender bias in child health investments against girl children in India. It also investigates how the effect of the supply shock on gender bias varies over time. To do this we exploit the variation in the implementation of the Integrated Child Development Services (ICDS) programme in India across both regions and time. Estimations are carried out at the child-level, using data from the 2005-06 round of the Measure Demographic and Health Survey (DHS) in India. We find that the increase in supply of vaccinations due to the programme initially increases the gender inequality in immunisation, but the increase disappears over time. We also find that the increase in gender disparity in the early stages of exposure is due to households vaccinating their sons before their daughters when the new supply of immunisations becomes available. Robustness checks are carried out using one-to-one propensity score matching methods and alternative child health investments to eliminate concerns of reverse causality, mean reversion, and bias due to omitted wealth factors. The major policy implication from our analysis is that a permanent supply increase generates a temporary increase in gender disparity that eventually disappears. However a temporary or short-term supply increase may irreversibly widen the gender gap in immunisation, and potentially further worsen the female-male sex ratio.
\end{abstract}

JEL classification: I18, J13, J16, O12

Keywords: Gender bias, child health, supply shock, immunisation, India

${ }^{*}$ We are grateful to Imran Rasul, Orazio Attanasio, Samuel Berlinski, and colleagues at the Department of Economics, University College London for their comments.

${ }^{\dagger}$ Contact: Department of Economics, University College London, Gower Street, London WC1E 6BT, United Kingdom. Email: a.chakravarty@ucl.ac.uk, Telephone: +44 (0)790 8567235. 


\section{Introduction}

It has been nearly 20 years since Amartya Sen claimed that "100 million women are missing" from the developing world (Sen (1990)). The population sex ratios in India, China, and other developing countries that led to this assertion have not changed over this period of time. In the 2001 census of India the female-male sex ratio (the number of females divided by the number of males in the population)was as low as 0.861 and 0.874 in the states of Haryana and Punjab respectively, and an even lower 0.821 in the national capital Delhi (Census of India (2001)). These figures stand in stark contrast to the prevailing figures of 1.05 and above in North America and Europe; areas where Sen points out that women are not subject to discrimination in basic nutrition and health care (Sen (1990)). The increased availability of prenatal sex determination technology has also led to the use of sex-selective abortions as a means of controlling the gender composition of offspring (Arnold et al (2002)). A recent study has postulated that up to 0.5 million female foetuses are aborted every year, despite sex-determination technologies such as amniocentesis being made illegal in India in 1994 (Jha et al (2006)).

Discrimination against Indian girl children in the provision of nutrition and health care is often identified as the root cause of the observed sex ratio imbalance in the economics literature. The literature on intra-household resource allocation in India has established a pattern of discrimination against girl children in the provision of nutrients (for e.g. see Rose (1999); Behrman (1998); Sen and Sengupta (1983); Rosenzweig and Schultz (1982)). The demography literature has also shown evidence that the bias against girls in India affects household fertility patterns, as well as provision of health investments such as breastfeeding and immunisation (Mishra et al (2004); Pande (2003); Marcoux (2002); Clark (2000); Arnold et al (1998); Das (1987)). This discrimination manifests in excess female child mortality, which creates the observed imbalance in the population sex ratio. Ray and Anderson (2008) provide an alternative point of view to the literature, arguing that the sex ratio in India is biased across all age groups and not just in the child population. However they argue that the bulk of the "missing women" in India can be explained by excess female deaths due to infectious disease; an assertion which they also admit does not rule out discrimination against girls in childhood which increases susceptibility to disease at older ages. We discuss the implications of our results for the findings in Ray and Anderson (2008) further in a later section.

We focus on gender bias in child immunisation in this paper, and pay particular attention 
to the effects of the Integrated Child Development Services (ICDS) programme initiated by the Indian government in 1975. The programme aims to universally provide child immunisation services, supplementary feeding and nutrition, and childcare education to young mothers across India. To do this, individual state governments are responsible for opening ICDS childcare centres, or anganwadi centres, to provide all these services in an integrated fashion to low-income families. ICDS is currently the largest early child care programme in the world, with over 748,000 centres operating across the country as of 2006 according to the Ministry of Women and Child Development (MWCD). ${ }^{1}$ We use the variation in the number of ICDS centres by region and the duration of ICDS centre operation to examine whether the policy reduces or intensifies the bias against girl children in health investments. We also use the policy variation to examine whether the effect of a permanent increase in healthcare supply on gender bias in immunisation is non-monotonic over time. We estimate the effects of the policy at the individual child level, using the 2005-06 Measure DHS dataset for India. The policy implications of this research are crucial. Increasing access to healthcare for children is an important part of the Millennium Development Goals. But if the effect of increased access is to worsen and make permanent already existing inequalities then additional solutions need to be found to prevent this from occurring.

The established link between poverty and gender discrimination across countries has led some to argue that increasing access to healthcare, via greater labour market opportunities or increased service coverage, will benefit women (World Bank (2001); Grown et al (2005)). However economic progress and rising incomes have not prevented the deterioration of the female sex ratio in the Indian population. In fact Punjab and Haryana, two states where the sex ratio is highly adverse, are also two of the wealthiest states in the Indian union in terms of per capita net domestic product (see Table 1). The effect of increased access to healthcare on gender inequality cannot therefore be argued to unambiguously beneficial. With this in mind the policy implications of increased healthcare supply for women's welfare need to be considered carefully. While greater access to healthcare may reduce excess child mortality, an integral component of the Millennium Development Goals, it may also further worsen the sex ratio if only male children receive the benefits.

This paper contributes to the literature on child health investments by analysing the

\footnotetext{
${ }^{1}$ Figures and information on the ICDS programme are provided by the Ministry of Women and Child Development, Government of India at http://wcd.nic.in/
} 
effects of a permanent healthcare supply increase on household gender bias in immunisation at the child-level. The response of the gender difference in immunisation to supply shocks has been addressed previously in Oster (2008). Oster analyses the effect of a continuous increase in healthcare supply on mean differences in immunisation between boys and girls at the village-level, using number of health camp visits to the village as a measure of healthcare supply. The results from Oster's analysis show a non-monotonic response with an initial increase in gender inequality that eventually dissipates. The nature of the supply shock we consider is qualitatively different. The ICDS programme provides a one-time discrete and permanent downward shock to the cost of immunisations for households, which is unlike the sporadic and gradual decrease in cost that is provided by an increasing number of village healthcare camps. The effect of a permanent discrete supply shock on gender bias in immunisations is yet to be examined. In addition, we explore whether the gender difference in immunisations responds non-monotonically to the duration of a permanent supply shock; an analysis which has also not yet been carried out. We find that exposure to the programme widens the male-female disparity in vaccinations by an average of 0.025 immunisations. The increase in gender difference appears to be driven by households that have been treated for the least amount of time. The disparity widens by 0.039 vaccinations on average for children in households treated for 5 years or less, but there is no such effect for households treated for longer periods.

Section 2 presents background information on the causes of gender bias against women in India, and details on the implementation of the ICDS programme. In section 3 we outline the theoretical model of child immunisation presented in Oster (2008), and discuss the possible effects of exposure to the healthcare supply shock on our comparative static of interest. Section 4 describes the data and the empirical methodology used in our analysis. The results from the analysis are presented in section 5. In section 6 we further investigate our results with additional estimations. Finally we discuss the implications of our results in section 7 .

\section{Background}

Gender bias in India is driven by a combination of sociocultural and economic factors which determines the net utility from each sex. Aside from the consumption value of children, parents broadly derive economic utility from their children from wage earnings, labour in 
agricultural production, and security in illness and old age (Bardhan (1974); Arnold et al (1998)). Sons traditionally stay with the family and work the household land or contribute to household earnings, and bring additional labour when the wife joins the household. Daughters on the other hand leave the home after marriage and work on the husband's land. There is also social utility derived from the kinship and descent system which is determined by the male bloodline. Sons therefore bring status and strength to the family, and ensure the continuation of the family dynasty (Dyson and Moore (1983); Caldwell et al (1989)). There is an additional premium brought to the household by male children in the form of a very large dowry at the time of marriage. Finally there are also religious benefits defined by various acts that may only be performed by sons. Hindu tradition dictates that only a son (or in the absence of a son, a male relative) may light the funeral pyre of his parents. Sons can also aid in the salvation of his parents souls by performing pind daan (donating food and clothing to brahmins and the poor) at particular times of the year.

In contrast to sons, daughters bring several costs to the household. The most important of these costs is a very large dowry that is customarily paid by the daughter's family to the husband's family at the time of marriage (Kishor (1995)). This dowry is traditionally very large (up to several multiples of annual earnings), and places a tremendous financial burden on the parents of the girl child. Also as mentioned previously, daughters become a part of their husband's household after marriage. Their labour on agricultural land is therefore lost to their natal household. There is an additional large opportunity cost of the time required to arrange a daughter's marriage, and to protect her chastity while she is unmarried. There is some religious encouragement to have daughters, as traditionally it is considered beneficial for a daughter to be present to weep at family funerals. The act of kanya daan, or sacrifice of the girl child at the time of her marriage, is also believed to bring the family religious merit (Dharmalingam (1996)). However the economic costs of girl children more often than not take precedence over these benefits.

From the point of view of economic efficiency, the differential returns from children based on their gender would induce parents to invest more in their sons to maximise their future stream of income. This gender disparity in child health investment is further accentuated by the cost of child health investments, which are large for a low-income family in India given the lack of healthcare supply in rural areas. The ICDS programme provides an exogenous downward shock in the cost of acquiring child health investments, and thus provides us with 
an opportunity to examine whether this decline in healthcare investment cost generates a non-monotonic response in the gender differential in immunisation.

\subsection{ICDS Programme}

The ICDS programme was begun in 1975, and is currently the world's largest early child development programme. The programme offers a package of health and educational services to children under the age of 6 and their mothers, all of which are provided at anganwadi centres which operate at the level of the village. The services offered include health check-ups, treatment of worms and diarrhea, growth monitoring, provision of micronutrient supplements, health and nutrition education to mothers, preschool education, and child immunisation. Since its inception the programme has been expanded extensively across India. The number of administrative blocks covered rose from 33 in 1975 to more than 6,118 in 2006 (MWCD (2009)). Government outlay on the programme was doubled in the 1990s. The budgetary allocation for the programme has been estimated at $\$ 230$ million in 199899 and \$170 million in 1999-2000 (Lokshin et al (2005)). By 2006 the programme services were being provided to 46.7 million children and 9.5 million pregnant and lactating women through 7.48 million anganwadi centres across the country (MWCD (2009)).

The ICDS programme has been evaluated previously with respect to its impact on child nutritional outcomes. Deolalikar (2004) finds 5\% reduction in the probability of boys being underweight in villages with an ICDS centre, but finds no significant association for girls. Lokshin et al (2005) however find no significant effect of the programme on nutritional outcomes upon using propensity score matching methods. Finally Bredenkamp et al (2005) find no significant difference in child nutritional status between ICDS and non-ICDS villages, but do find a positive effect of the programme for children below the age of 3 years who actually participate in it regularly. ${ }^{2}$ The impact of the programme on child immunisation has yet to be empirically investigated.

An important aspect of the programme that is relevant for our analysis is how it is placed regionally. Specifically, since we are analysing the effects of the programme on gender bias in immunisation, we must ensure that the programme is not targeted to areas with high gender differences in immunisation levels. According to the official programme policy the targeted beneficiaries are children up to the age of 6 , pregnant women, and mothers

\footnotetext{
${ }^{2}$ This is a work in progress that the authors do note wish to be cited as yet
} 
who belong to the poorest sections of society and reside in backward rural and tribal areas or urban slums. Lokshin et al (2005) is the only paper in the ICDS literature we are aware of that attempts to control for programme placement based on household and village characteristics using propensity score matching methods. While there is no explicit evidence that the programme also targets populations where girl children are discriminated against with respect to immunisation or other health inputs, it is possible that it does so incidentally if such gender discrimination is more severe among poorer communities. Such targeting would bias our results due to reverse causality and mean reversion. To alleviate concerns regarding these sources of bias we use propensity score matching methods to ensure that the treated and untreated population share a common support in the observables that determine selection into ICDS coverage, and to eliminate concerns of greater pre-existing gender bias in immunisation before treatment. We also carry out robustness checks on the probability of programme coverage at the household, village, and state level. The results of these analyses are presented in our robustness checks section.

\section{Theoretical Framework}

We outline the model of continuous child health investments presented in Oster (2008). We assume that households receive $\phi_{b}$ level of utility from each son, and $\phi_{g}$ from each daughter. To reflect the prevailing bias against girl children, we assume that the utility from sons is greater than that from daughters:

$$
\phi_{b}>\phi_{g}
$$

The household chooses number of vaccinations $n \in[0,9]$ for each child, and consumption level $c$ to maximise its utility. ${ }^{3}$ The probability of child survival is given by the function $f(n)$ where $f^{\prime}(n)>0$. Given that the number of vaccinations is bounded, we also assume that $f(0)=p_{0}$ and $f(9)=\bar{p}$. This corresponds to the case of continuous child investment with saturation as described in Oster(2008). The price for each unit of $n$ is $v$, measured in units of consumption. The household's maximisation programme is:

$$
\begin{gathered}
\max _{c, n} u(c)+\phi_{s} f(n) \\
\text { s.t. } \quad c+n v=Y
\end{gathered}
$$

\footnotetext{
${ }^{3}$ There are nine total vaccinations recorded in our dataset.
} 
Here, $s \in\{b, g\}$ denotes the sex of the child. The above programme yields the simple first order condition: $\phi_{s} f^{\prime}(n)=v$. From the assumptions placed on gender-specific utility from children, it is clear that we will have $n_{b}^{*}>n_{g}^{*}$ in equilibrium. Our initial object of interest is the direction of the change in this gender differential in immunisation level when the price of immunisation $v$ changes. We are therefore interested in the sign of the comparative static $\frac{d\left(n_{b}^{*}-n_{g}^{*}\right)}{d v}$.

\subsection{Gender Inequality Response to Supply Shock}

There are two possibilities for the response of the gender difference in vaccinations to the fall in price, assuming that the fall is large enough to induce a response. Given that we are considering a discrete shock to price, the gender differential in immunisation will increase or decrease depending on the initial price of immunisation before the shock takes place. Both possible cases are discussed below. ${ }^{4}$

\section{Case I: Increase in Gender Inequality}

Let $v$ take on a value high enough so that there is no immunisation for either girls or boys in equilibrium: $v>\phi_{b} f^{\prime}(0)>\phi_{g} f^{\prime}(0)$. At this value of $v$ there is also therefore no gender inequality in immunisation levels. As the value of $v$ decreases there will come a point where $\phi_{b} f^{\prime}(0)>v>\phi_{g} f^{\prime}(0)$. Within this interval of values for $v$ we will have $n_{b}^{*}>0$ and $n_{g}^{*}=0$, thus generating inequality.

\section{Case II: Decrease in Gender Inequality}

Let $v$ take on a value that is low enough so that there is full immunisation for boys in equilibrium, but not girls: $\phi_{b} f^{\prime}(9)>v>\phi_{g} f^{\prime}(9)$. Within this interval of values for $v$, we have $n_{b}^{*}=9$ and $n_{g}^{*}=0$ in equilibrium. As the value of $v$ decreases from this point the number of vaccinations to boys will not increase since it is already at the maximum, but the number of vaccinations to girls will increase until $n_{g}^{*}=9$. Hence we will have declining inequality.

\footnotetext{
${ }^{4}$ Since the ICDS programme has been expanded steadily on annual basis, it is also possible that a gradual lowering of household expected price takes place before treatment. However this does not change our framework as long as the immunisation decision is made based on the observed price. We additionally disregard consumption in the presentation of both cases for the sake of simplicity, even though further testable restrictions may be generated by its inclusion.
} 
Oster (2008) shows that the above predictions hold regardless of whether $f(n)$ is linear or non-linear. We will now analyse the possible second order effects of the duration of the price shock on gender bias in immunisation.

\section{Data and Empirical Strategy}

We use the 2005-06 round of the Measure DHS survey in India, which contains detailed birth histories, child health, and maternal health information for over 100,000 women aged 15-49 years. Detailed immunisation information is available for all births in the six years preceding the survey. Information on whether the household is covered by an ICDS centre and the number of years the ICDS centre has been open is also available. We restrict the sample to women who are currently married and have only been married once. We also only retain women who have had a total of six births or less as the sample size shrinks rapidly by birth order after this point. ${ }^{5}$

Figure 1 shows the number of new villages introduced to the ICDS programme every year from the sample described above since the inception of the programme in 1975 . In the first six years of the programme barring 1980, less than 50 new villages were covered by the programme annually. 1982 appears to be unusual year, with 233 villages in our sample being introduced to programme coverage. The number of villages included in the programme annually then becomes more stable.

The set of vaccines supplied by the government and delivered to households via the ICDS programme was only finalised in 1985. The Expanded Programme on Immunisation (EPI) begun in 1978 introduced a supply of the BCG, DPT, and oral Polio vaccines to urban areas. The Measles vaccine was added in 1985 with the initiation of the Universal Immunisation Programme (UIP) which aimed to provide a supply of vaccines to all parts of the country (WHO (2005)). To preserve comparability of the ICDS programme's effect across different years, we remove women who have been treated since before 1986 from the sample. This leaves us with a twenty year period to analyse programme effects. This length of time period for our analysis also serves to create symmetric five-year categories by length of coverage, and remove the early outlier years of programme implementation from the sample.

\footnotetext{
${ }^{5}$ The full sample consists of 124,385 women. We remove 36,460 women who are not currently married, and an additional 1,868 women who have been married more than once. Restricting the sample of children born during 2001-2006 by birth order leaves us with 33,685 women (or households) and 46,879 children.
} 


\subsection{Immunisations and Household Characteristics}

There are nine total vaccinations on which data is collected for children born during the period 2001-2006, the six years leading up to the survey. These are the BCG vaccine, Measles vaccine, four rounds of the Polio vaccine, and three rounds of the DPT vaccine. We use the total number of vaccinations received by children born during these years as our measure of child health investment. Mean vaccination levels by child gender for each of the six birth cohorts in the sample trimmed by birth order and marriage are presented in Table 2, For every cohort barring that born in 2006 the mean number of vaccinations received by boys is greater than the mean for girls, with boys receiving $0.10-0.30$ more vaccinations on average. For the cohorts born in 2001, 2003, and 2005 the difference in means is statistically significant. The lack of a similar difference in immunisation levels for the youngest cohort is not surprising, as vaccinations are acquired over time.

In Table 3 we present and test the differences between the proportions of boys and girls that have received all nine vaccinations by birth cohort. This sheds light on the extent of gender preference households exhibit in providing complete protection to their children against disease; an alternative point of view to gender-differentiated timing in immunisation. Again, except for the 2006 cohort, the difference is positive in favour of boys for all the re-

maining birth cohorts. The difference in proportions is also statistically significant for the cohorts born in 2004 and 2005.

The total number of villages and households in the trimmed sample, along with figures on ICDS coverage, are reported in Table 4. There are a total of 3,056 villages, of which 1,999 have an ICDS centre. 27,495 households and 38,435 children make up the final sample. We divide villages covered by the ICDS programme into categories based on years of coverage by five-year intervals to isolate the effect of duration of exposure to the policy. There are more than 400 villages and 5,000 children in each of the four categories, yielding enough variation for a meaningful comparison.

Descriptive statistics of important determinants of parental demand for child immunisation from the trimmed sample are shown in Table 5. Mother's educational attainment takes integer values from 0 to 5 , where 0 indicates no education and 5 indicates education beyond secondary school. Birth order is measured in ascending order, with smaller numbers denoting older births. Other variables include the succeeding and preceding birth intervals 
in months, mother's age in years at the time of the child's birth, and the mother's report of the child's smallness at the time of birth. These variables help us to ascertain the child's health endowment, which is a crucial determinant of health investment. Finally we also consider various sibling composition variables such as previous living sons and previous living children, which have been shown to affect demand for child health investments in India given the prevailing bias against girl children.

In Table 6 we present the differences in means and proportions of various household and mother characteristics by ICDS coverage. Nearly all the differences are highly significant, illustrating that the programme is targeted to low income households. Mothers in ICDS covered villages are much likelier to live in a rural area, to have married younger, to have given birth earlier, and to live in a house with a floor made of dirt or clay. They are also much less likely to have completed primary or secondary education, or live in a household that owns a radio, motorcycle, car, or refrigerator. We therefore attempt to control for several household wealth indicators in our analysis.

While we cannot be certain that we have included all possible wealth indicators that determine selection into treatment, we will present evidence in a later section to argue that any omitted wealth factors will not bias our coefficients of interest. The argument for this is based on the fact that while gender bias against girls is driven partly by economic factors, there is no empirical evidence indicating either a positive or a negative relationship between the intensity of gender bias and the level of household wealth. This would imply that the household response to the ICDS programme is purely driven by the change in the price of immunisations, and is uncorrelated with existing levels of wealth. Additionally, our theoretical framework predicts that at low levels of supply there is no gender bias in immunisation. We should therefore expect to find no gender disparity within households at the lower end of the income distribution to whom the ICDS programme is targeted, as they reside in low-supply areas. ${ }^{6}$ Combined with the fact that the programme increases supply without altering the wealth holdings or income levels of treated households, this allows us to be reasonably confident that we are capturing household response to a supply change and not any unobserved wealth effects.

\footnotetext{
${ }^{6}$ Evidence of this is presented in our robustness checks, when we attempt to rule out pre-existing gender differences in immunisation as a source of bias for our results.
} 
Table 7 shows the timeline for child immunisation as recommended by the Indian government. By the age of 36 weeks, or 9 months, children are meant to receive all the nine immunisations we are using for our analysis. There are therefore enough children in our sample who are old enough to have received a significant number of these immunisations, and to pick up any differential trends created by the increase in supply.

\subsection{Empirical Strategy}

To estimate the first order effect of the programme on gender bias in immunisation, we use the following specification:

$$
I_{i h}=\beta_{1} \operatorname{girl}_{i h}+\beta_{2} I C D S_{h}{ }^{*} \operatorname{girl}_{i h}+\gamma_{1} X_{i h}+\eta_{h}+\theta_{i}+\epsilon_{i h}
$$

$I_{i h}$ is the number of vaccinations received by child $i$ in household $h$, where each mother in the sample is treated as a single household. The dummy variable girl $l_{i h}$ equals 1 when child $i$ is a girl. ICD $S_{h}$ is a dummy variable for whether the household is covered by an ICDS centre. In addition to these regressors, we include a vector of child-specific and household covariates $X_{i h}$ and a household (or mother) fixed effect $\eta_{h}$. Child-specific unobservables are included in $\theta_{i}$, and $\epsilon_{i h}$ is an idiosyncratic error term.

The beta coefficients in (3) will allow us to ascertain the effect of child gender on child immunisation level, and the marginal effect of ICDS policy coverage on any prevailing gender bias in immunisation. The $X_{i h}$ vector contains various other household and child-specific variables that may influence the number of vaccinations child $i$ receives, such as number of previous children and previous sons, a dummy variable for whether there is at least one previous living son, birth order, and mother's education and age. In addition to controlling for birth order and sibling sex composition, we also include a dummy variable for whether the child in question is the first-born child to the household. This is to control for the documented parental bias in favour of the first born child.

To capture the effect of child gender on demand for immunisation without any bias or confounding effects, we must attempt to control for the child's health endowment as best as we can. To do this we include the variables discussed previously, namely preceding and succeeding birth intervals, mother's age at birth, and mother's report of child smallness. While other studies have relied on birth weight rather than reported birth size, we argue that 
the latter is the correct variable to use as it is the parents' perception of the child's health endowment that influences their decision to immunise. Finally to control for the effects of household wealth on immunisation and the probability of ICDS centre coverage, we include several household wealth indicators such as whether the household owns a refrigerator, a radio, a bicycle, or a car, the materials from which the house is constructed, the form of toilet in the house, and whether the household has electricity. Regional effects are controlled for by including village fixed effects.

It is possible that there are still omitted household unobservables that influence both gender bias and the level of child immunisation. Including the household (or mother) fixed effect $\eta_{h}$ allows us to control for these potential sources of bias, but doing so also mitigates the household response to the price shock that is driven by other unobservables such as traditional attitudes or personal biases. As this is precisely the household response we want to capture, including the household fixed effect may dampen our coefficient of interest. We therefore present results from estimations with both village fixed effects and household fixed effects, and compare coefficients to address concerns of any bias due to excluded household variables.

There is also a concern that child-specific unobservables in $\theta_{i}$ bias all the coefficients of interest. These unobservables are part of the combined error term $u_{i h}=\theta_{i}+\epsilon_{i h}$ which is possibly correlated with the regressors. We minimise this possible source of bias by including child-specific regressors that control for the health endowment at birth and birth year dummy variables. It is anyway very unlikely that child-specific heterogeneity is correlated with the probability of ICDS coverage once regional and household variables are controlled

for. It is also reasonable to assume that child-specific heterogeneity is uncorrelated with child gender, once health endowments at birth are controlled for.

We now turn to the analysis of the dynamic effects of the ICDS programme on the gender disparity in immunisation, and discuss the possible causes of a non-monotonic response of the latter to the former over time.

\subsection{Dynamic Effect of Supply Shock on Gender Inequality}

Logically the response of the gender difference in immunisation to a permanent price shock should vary with duration of exposure to the shock. Lags in information dissemination or 
lack of awareness may prevent households from immediately taking advantage of the new supply of child vaccines. Or it is possible that when the new supply becomes available, the initial response of households is much larger than in later periods due to pent-up demand. To examine whether the programme effect on the gender difference is sensitive to duration of exposure, we expand the specification in (3) to include the second order effects of time as follows:

$$
\begin{aligned}
I_{i h}= & \beta_{1} \text { girl }_{i h}+\beta_{2} I_{C D S_{h}}{ }^{*} \text { girl }_{i h} \\
& +\beta_{3} I C D S_{h}{ }^{*} I C D S_{h, 0-5}{ }^{*} \text { girl }_{i h} \\
& +\beta_{4} I C D S_{h}{ }^{*} I C D S_{h, 6-10}{ }^{*} \text { girl }_{i h} \\
& +\beta_{5} I C D S_{h}^{*} I C D S_{h, 11-15}{ }^{*} \text { girl }_{i h} \\
& +\gamma_{1} X_{i h}+\eta_{h}+\theta_{i}+\epsilon_{i h}
\end{aligned}
$$

Here, $I C D S_{h, 0-5}$ is a dummy variable which equals 1 if the ICDS centre has been open for 0-5 years. Similarly, $I C D S_{h, 6-10}$ and $I C D S_{h, 11-15}$ are dummy variables which equal 1 when the ICDS centre has been open 6-10 years or 11-15 years respectively. The omitted category is ICDS centres that have been open for 16-20 years.

We have already shown in our theoretical framework that when the initial value of $v$ is high enough, gender inequality will increase when $v$ decreases. There are two possible second-order effects of time on this increase. The first is that the increase in gender inequality is further amplified by longer duration of exposure. We may observe such an effect for various reasons, such as greater returns to health investments in male children as compared to girls which are only revealed when the children are older. Given the high initial cost of immunisation before the supply increase, low rates of child immunisation may have prevented households from observing these returns previously. Another possible reason is that households only become aware of the supply increase over time, and then choose to immunise their sons rather than their daughters. The second possibility is that the increase in gender disparity dissipates over time. This could again be due to pent-up demand for immunisations when the supply shock occurs, which leads households to immunise their sons more than their daughters. Given that the initial cost of immunisation is high in this case, there would most likely be a large number of unvaccinated children at the time of the supply increase. Hence we would observe a sharp increase in inequality if a very large number of 
boys were vaccinated as compared to girls. This increase would disappear over time if more girls were vaccinated after the initial period where boys received the first immunisations.

We now discuss Case II from the previous section, where $v$ is low enough initially so that boys are vaccinated, but not girls. After the downward shock to immunisation cost, we have seen that gender inequality will decline due to the upper bound on the number of possible immunisations. The decline in gender inequality could either slow down or gain speed with greater duration of exposure to the supply shock. One possible way the former might happen is if households use the increase in supply of immunisations to immediately equalise the number of vaccinations to boys and girls, which would initially create a sharp decline in gender inequality that would slow over time as the number of previously unvaccinated children declines. The latter could be caused by a delay in households awareness of the supply shock or gender-specific additional gains to the health of girl children that are only observed at a later stage.

To be able to accurately interpret our results regarding duration of exposure to the ICDS programme, we must make the parallel trend assumption which is commonly made in the programme evaluation literature. Specifically we assume that the trend in the gender difference in vaccinations is the same between covered and non-covered villages over time prior to introduction of the programme. Without this assumption we cannot be sure if we are capturing the dynamic effect of the programme on gender bias, or simply different dynamic trends in the gender difference in immunisation between treated and untreated villages. The assumption is reasonable given that local healthcare supply conditions are unlikely to have changed in treated villages prior to the introduction of the programme. In untreated villages where supply is low the theoretical framework predicts that neither boys nor girls will receive vaccinations due to high costs, which would imply a constant zero gender difference in immunisations over time. Similarly in untreated villages where supply is plentiful, the theory predicts that both girls and boys will be vaccinated fully leading to a zero difference over time. Hence the parallel trend assumption essentially applies to villages where supply is such that the price causes boys to be vaccinated significantly more than girls. The assumption is satisfied if the gender difference in these areas remains constant over time; a condition which is likely to be satisfied given that the number of possible immunisations is bounded from above, and that the social and economic factors determining the gender-specific stream of returns from children are very slow to change over time. It can be argued that the as- 
sumption is a strong one to make given the differences between the treated and untreated populations shown in Table 6. However results are presented in section 6 which verify that we are actually capturing the effects of the programme, and not simply the effects of time.

We estimate the specifications in (3) and (4) using a Poisson event count data model. We first present estimations without any of the ICDS coverage regressors to establish that there is indeed a bias against girl children in immunisation within our sample, and also to verify the identifying strength of the specification. The full specifications are then estimated with the relevant policy regressors. Results are reported for each specification with both village and household fixed effects. As the ICDS centre coverage for households is reported at the level of the village (the primary sampling unit) within each state, we cluster the standard errors at the village level. The results are discussed in the next section.

\section{Results}

Table 8 presents results from the estimation of (3) without the ICDS coverage regressors. In both the specification with village fixed effects and the specification with household fixed effects, the coefficient on the girl child indicator is negative and significant with girls receiving 0.020-0.023 fewer vaccinations on average. Sex composition within household offspring is predictably an important determinant of immunisation level in the village fixed effect specification, with the average number of immunisations to each child declining by 0.086 with each previous living son. There is however a a positive effect of 0.061 vaccinations of having at least one previous living son. This seems to indicate that households want to ensure that at least one of their sons survives, which then improves the chances of other children being immunised. However as the number of living sons increases, the household's perceived need to insure their remaining children's health declines. Being a first-born child also significantly increases the number of vaccinations received. With respect to child health endowments, both mother's age at birth and reported smallness at birth have the expected negative sign and are significant. The length of the preceding birth interval has a positive and significant effect on child immunisation, but the size of the effect is very close to zero. With regard to the household fixed effect specification, the coefficients are however not readily comparable to those in the village fixed effect specification as the estimation procedure with household 
fixed effects only uses households with more than two births in the years 2001-2006. ${ }^{7}$ Hence the sample size diminishes greatly, and the households included are likely to be qualitatively different from those that are excluded. The differences in sign and size of some of the coefficients from the village fixed effect specification are therefore partly attributable to this, and not just because we have controlled for additional household unobservables.

The marginal effects of the ICDS programme on gender-specific immunisation are reported in Table 9. The first three columns show the results after including the ICDS dummy variable interacted with girl child gender dummy to pick up the first-order gender effects of the supply shock. The first column shows estimates from the full sample of children with village fixed effects. In this specification, the interaction term is negative and significant. The introduction of the new supply of vaccines via the ICDS programme intensifies the bias against girl children by an average 0.025 vaccinations. To control for potential time-invariant household unobservables that are correlated with gender bias and also with immunisation, we estimate the same specification with household fixed effects. The results are shown in the third column. As mentioned previously, the household fixed effect controls for various unmeasurable factors that drive the parental response to the price shock such as attitudes and cultural factors. Hence upon its inclusion the first order interaction term becomes insignificant. To illustrate this we re-estimate the specification on the sample of children from households with two or more births during 2001-2006, but with village fixed effects. The results are presented in the second column. The ICDS-gender interaction is again negative and significant, and in fact larger than the estimate from the full sample. We can therefore assert that the effect of the price shock is to worsen gender bias against girl children in immunisation.

The fourth, fifth, and sixth columns of Table 9 show results from the same estimations as in the first three columns after including the three-way ICDS programme interaction terms that reveal the second-order effects of duration of coverage. In all three specifications, the intensifying effect of the ICDS policy on gender bias appears to the greatest for households that have been covered for a shorter period of time as opposed to a longer period. The girls

\footnotetext{
${ }^{7}$ We were unable to achieve convergence during the estimation when including mother's age at birth, most likely due to lack of variation or collinearity with other regressors. However we estimated the specification again including this variable but without robust standard errors to simplify the algorithm, and this did not change the values of the other coefficient estimates. Hence we can be reasonably confident that they are not biased by the exclusion of this regressor.
} 
who have been exposed to ICDS coverage for 0-5 years receive 0.039-0.067 vaccinations less

on average as compared to girls who have been exposed for 6 years or more. The village fixed effect results from the sample of children from households with two or more births since 2001 again yields the largest estimated average reduction of 0.078 vaccinations. These results can be considered to be analogous to that in Oster (2008), where gender bias is worsened with the initial marginal increase in supply and then decreases at higher levels of supply. In our case the one-time shock in price has a strong short term effect on gender bias, which disappears over time.

To control for the gender-specific effects of other policies on immunisation, we estimate the specification again after including state indicators interacted with the gender dummy. This is the best we can do without more specific village-level information on additional government policies. However this also means that we are additionally controlling for regional cultural norms that drive gender bias in health investments, and therefore possibly dampening our coefficients of interest. The results from this estimation are presented in Table 10. After including the state-gender interaction terms, the ICDS programme still appears to widen the gender disparity in immunisation by an average of 0.023 vaccinations. The term for coverage of $0-5$ years interacted with the gender indicator is also still negative and marginally significant. We can therefore conclude that our results are not being influenced by other unobserved policies.

\subsection{Robustness Checks}

Our results are subject to weakness if the ICDS programme is placed first in areas where gender bias in child health investments is most severe. This would mean our results are being driven by reverse causality. There is nothing in the programme literature to indicate that the timing of the introduction of the programme to villages is influenced by regional conditions, including gender bias in health investments. However to ensure that this is not the case we run placebo fixed effect OLS regressions with the same specification, but with months of breastfeeding and child birth weight in grams as dependent variables. There is a well documented gender bias against girls in breastfeeding in India, and girl child birth weights are also known to be much lower than those of boys. Implementing these regressions can alleviate the concern that the policy is targeted, and also eliminate the possibility that the results are driven by unobservables that are simultaneously correlated with gender bias 
as well as the ICDS coverage variables. The results are presented in Table 11. The disadvantage to girl children in both breastfeeding and birth weight is evident in the results from the specifications without the ICDS programme indicators in the first and fourth columns. However, none of the programme related regressors are significant in the regressions with months of breastfeeding as the dependent variable. The same is true with birth weight. The first order effect of the ICDS programme is insignificant, and so are all the terms for length of programme coverage. These results provide assurance that the programme is not targeted to areas with higher gender bias.

To be more certain we use data from the previous two waves of the DHS surveys in India to run one more robustness check. We implement an OLS estimation of the number of ICDS centres in each state in 1998-99 on the mean immunisation level, and also the difference in mean vaccinations between girls and boys in each state in 1992-93. We include in the specification various state-level mean characteristics that could potentially influence ICDS coverage, such as average village distance from the nearest town, railway station, primary health centre, hospital, and bus stop. We also control for the probability of the village being electrified, and the availability of all-weather and paved roads. Finally to capture the fact that the programme is targeted to low income households, we include the state average as well as the average gender difference in child weight-age percentile in 1992-93. Ideally we would like to use average characteristics for smaller geographical units, but district matching across these two waves of the DHS survey is not possible. The results are presented in Table 12. The estimates in the first column reveal that ICDS centres appear to be targeted to areas with the lowest mean vaccination and weight-age percentile levels. This is intuitive given that the programme is meant to aid poor households. However neither the gender difference in mean immunisation nor the gender difference in weight-age percentile are significant in determining the number of ICDS centres. Introducing quadratic terms in both mean vaccinations and the mean gender difference in vaccinations in column two render all the estimates insignificant. This provides us with further evidence that gender bias is not a determinant of where ICDS centres are placed.

\subsection{ICDS Programme Placement and Pre-Treatment Gender Bias}

The evidence presented in the previous section bolsters the validity of our results. However to be even more certain that our results are not driven by greater pre-existing gender disparity in immunisations in treatment areas, we use propensity score matching methods to 
examine the existing levels of gender bias in a constructed control group of households. Using one-to-one matching methods we estimate the propensity score of selection into treatment using several variables including state fixed effects, household wealth indicators, mother's education, and religion and caste indicators. The post-matching histogram for treated and untreated children is shown in Figure 2, The variables we use to predict selection into treatment perform very well with about $77 \%$ of treated children having a propensity score of 0.75 or more, and nearly $45 \%$ of treated children having a score of 0.90 or more. Out of the total sample of 38,435 children only 28 do not appear to share a common support on the observables. About 28.5\% of untreated children have a propensity score greater than 0.65 , yielding a large enough control group for the purpose of comparison with treated children.

There are two main concerns regarding programme placement that may bias our results. The first is that the programme is targeted to areas with higher pre-existing gender bias, leading to reverse causality. This potential source of bias has been addressed to some extent in the previous section. The second concern is that the households selected into treatment for some reason may have had lower levels of prevailing gender disparity in immunisation before being exposed to the programme as compared to similar control households. This would imply that our result is being driven by mean reversion, as gender bias in immunisation measured post-treatment may simply be at par with that in households that are likely to be treated. We first examine mean gender differences in immunisation and the probability of being fully vaccinated in untreated households by propensity score to see if there is evidence of pre-existing gender bias before selection into treatment. We only use children born in 2005 or before to ensure that they are old enough to have received all nine vaccinations. The gender differences in mean immunisation are reported in Table 13. At no level of minimum propensity score above 0.70 are the mean gender differences significant. The corresponding gender differences in proportion of children fully immunised are reported in Table 14. Again, none of the proportions are significantly different within untreated children for any minimum propensity score greater than or equal to 0.70 . Hence there does not seem to be any descriptive evidence of gender bias against girls in immunisation in our control households. This is consistent with our theoretical framework, which predicts no gender bias in areas with low healthcare supply and high price of immunisation.

To further ensure that the results are not driven by pre-existing gender bias we estimate the specification in (3) on sub-samples of treated and untreated children trimmed by propen- 
sity score. Our main regressor of interest is the gender indicator, so we omit all programme related regressors. We then compare the level of the gender disparity in immunisation in the treated sub-samples to their corresponding control groups in the untreated sub-samples. The results from these estimations are presented in Table 15. The coefficient on the gender indicator is negative and highly significant in all three sub-samples for treated children. Girls receive an average of 0.026 fewer vaccinations than boys within treated children with a minimum propensity score of 0.85 , and $0.032-0.033$ fewer vaccinations within the treated sub-samples with minimum propensity scores of 0.65 and 0.75 . On the other there appears to be no gender bias in immunisation within the corresponding control sub-samples of untreated children. In all three estimations the gender indicator has a coefficient very close to zero and is highly insignificant. This provides more conclusive evidence that there is no pre-existing gender bias in immunisation in untreated areas that are highly likely to be selected into treatment. We can therefore be confident that our results are not driven by mean reversion or reverse causality.

\subsection{Gender Bias and Wealth Effects}

While we have controlled for several household wealth indicators, it is possible that there are still some omitted variables measuring household wealth status in the error term of our specification. These omitted variables could potentially bias our estimates if the intensity of gender bias in immunisation is correlated with the level of household wealth. For example if the supply shock actually has no effect on the gender difference in vaccinations, but the gender disparity is greater for households with smaller wealth holdings, then the coefficient on the ICDS-gender interaction will be biased downward as the programme is targeted to poor households. This is a possible reason for the negative and significant effect we find for this interaction term. In this section we discuss some of the existing empirical evidence on the relationship between household wealth and gender bias, and perform additional robustness checks to rule out this potential source of bias.

There has not been a significant amount of empirical research on the effect of poverty on gender discrimination in India. Within the literature that exists, there is a tentative hypothesis that gender bias is less severe in poorer households (Krishnaji (1987); Miller (1993); Dasgupta (1993)). Others have argued that poverty is not a significant determinant of gender bias (Das Gupta (1987)). Rose (2000) presents evidence that income shocks have a greater adverse effect on girl child survival probabilities in rural landless households than in 
those with land holdings. However this provides little insight on how existing levels of gender bias vary by household wealth status prior to these income shocks. Murthi et al (1995) find that female child survival probabilities improve with greater household poverty, lending further support to notion that gender bias is more intense at higher levels of income. However it is difficult to conclusively accept this hypothesis without more empirical investigation.

With regard to our own results, there are several factors that reduce the possibility of bias due to unobserved wealth factors. We have already shown that there is little trace of any pre-existent gender disparity in immunisation in untreated areas that are likely to be selected for ICDS coverage. This provides some additional cause to believe that gender bias may be less intense in poorer households. To further explore the possible effects of omitted household wealth variables, we re-estimate the specification in (3) with an increased number of wealth indicators and analyse the change in our coefficients of interest. The results both with and without the ICDS-gender interaction term are presented in Table 16.

Columns (1) and (2) show the results from our original estimations with the initial set of chosen household indicators. As expected nearly all the indicators significantly increase the number of child immunisations. In columns (3) and (4) we introduce four new indicators of wealth; whether the household owns a chair, a cot or bed, a pressure cooker, or a tractor. Increasing the number of wealth indicators in the specification leaves the coefficients on both the gender indicator and the ICDS-gender interaction almost completely unchanged. In fact the interaction term is marginally more negative than in the original specification. Also including these additional wealth indicators in the specification renders several of the originally chosen indicators significant. This signifies a high degree of collinearity between the various indicators of household wealth. Hence we can argue that our original set of wealth indicators adequately capture nearly all the household wealth effects, leaving little concern of omitted variables in the error term. In columns (5) and (6) we include the DHS household standard of living index, which is calculated based on several indicators of household wealth. ${ }^{8}$ This variable is the nearest we can come to a complete measure of household wealth status in our dataset. Again, the inclusion of this regressor makes nearly all of the previously included wealth indicators insignificant due to collinearity. The gender indicator also becomes marginally more negative as a result, but the change is negligibly small. The coeffi-

\footnotetext{
${ }^{8}$ The standard of living index is calculated by aggregating scores assigned to various household assets such as livestock, agricultural land, and consumer durables. For more details see the National Family and Health Survey 3 (NFHS3) supplemental documentation.
} 
cient ICDS-gender interaction term remains completely unchanged from columns (3) and (4).

The fact that altering the number of wealth indicators in our specification does little to change our estimates of the gender disparity in immunisation, or the estimated effect of the programme on this gender difference, goes a considerable distance in showing that gender bias does not change with household wealth. If anything our estimates become slightly stronger, which implies that any unobserved wealth effects may only be weakening our results instead of driving them. While there is scope for further empirical work investigating the relationship between household poverty and gender bias, our findings appear to be in line with the literature that does already exist on the subject.

\section{ICDS and Increased Inequality: Timing of Child Im- munisation}

We now explore further the reasons behind the initial increase in gender inequality after the introduction of the ICDS programme. The most convincing explanation, which is also argued for in Oster (2008), is that upon introduction of the new supply of vaccines households choose to vaccinate their sons before their daughters. This would create the initial widening of the gender gap in immunisation that we find; especially if there are a large number of unvaccinated children eligible for inoculation at the time of the introduction of the programme. To investigate whether this is the case, we restrict our attention to only households covered by the ICDS programme and estimate the following specification:

$$
\begin{aligned}
I_{i h}= & \beta_{1} I C D S_{h, 0-5}+\beta_{2} I C D S_{h, 6-10}+\beta_{3} I C D S_{h, 11-15} \\
& +\beta_{4} I C D S_{h, 0-5} * \operatorname{girl}_{i h}+\beta_{5} I C D S_{h, 6-10}{ }^{*} \operatorname{girl}_{i h}+\beta_{6} I C D S_{h, 11-15}{ }^{*} \text { girl }_{i h} \\
& +\gamma_{1} X_{i h}+t_{h}+\epsilon_{i h}
\end{aligned}
$$

The regressors here are the same as in the previous estimations. $t_{h}$ is a dummy variable which is equal to one if household $h$ was introduced to ICDS coverage in year $t$, and zero otherwise. The effect of duration of exposure to the programme on immunisation will be captured by the first three regressors, which are the dummy variables for coverage by fiveyear categories. Interacting these regressors with the indicator for a girl child show whether the effect of duration of exposure is different for girls than for boys. Specifically it will 
allow us to verify whether the order in which children are vaccinated is influenced by the child's gender. Inclusion of the dummy variable $t_{h}$ controls for unobservables that may have influenced the choice of the specific year to introduce the programme to the village where household $h$ resides. We estimate (5) with state fixed effects.

The results from this estimation are presented in Table 17. The first column presents results from the estimation without the ICDS duration-gender interaction terms. The coefficient on the dummy variable for coverage for $0-5$ years is negative and significant, indicating that children within the treated population who have been exposed to the programme for less time have fewer vaccinations. This is an intuitive result, as ICDS centres may not have been open long enough in these villages for households to obtain as many vaccinations for their children as in villages where the supply has been available for longer.

The second column presents the results from the estimation of the full specification. The girl child interaction terms for households covered by the programme for 0-5 years and 6-10 years are both negative and significant. This shows that within the first ten years of being introduced to the programme, households vaccinate their sons more than their daughters. However since the coefficient on the term for coverage of 6-10 years in insignificant in column 1, total child vaccinations in households exposed for this length of time are at the same level as those covered for 16 years or more. This means that the entire increase in number of child vaccinations between households covered for 0-5 years and those covered for 6-10 years is driven only by a greater number of boys being vaccinated. The gender difference is greatest for households covered for 0-5 years, and becomes smaller over the next five years of programme coverage. The disparity seems to disappear only after households have been covered for more than ten years.

We can conclude from the above results that the observed initial increase in gender inequality in immunisation is due to households inoculating their sons before their daughters upon introduction of the new supply of immunisations. Sons and daughters appear to be vaccinated equally in households that have been covered by the programme for more than ten years. These results also verify that our findings are driven by the effect of the ICDS programme, and are not just reflecting the trend in immunisations to boys and girls over time. 


\section{Discussion}

Our results indicate that households that receive ICDS coverage have little or no access to child immunisations before the supply shock. The increase in supply and accompanying fall in price therefore cause not only the total number of vaccinations to increase, but also the gender difference in vaccinations as per Case I in our theoretical framework. However the gender differential that is created by the increase in supply disappears over time. The mechanism by which the gender disparity increases is that households immunise their sons before their daughters in the initial stages of exposure to the ICDS programme. Daughters and sons are immunised on a more equal basis in areas where the programme has been in operation for longer.

The policy implications of these results are important with regard to commitment and length of planned health interventions. In countries such as India where gender bias in child health investment is endemic, a sudden increase in healthcare supply where availability was previously low may have adverse effects on equality in the short run. However if the increase in supply is sustained over time equality in health investment levels is reestablished, ostensibly at a higher level of investment than previous to the supply shock. Hence policy interventions such as the ICDS programme which are permanent or sufficiently long lasting can achieve higher child health investment levels with only short term consequences for inequality.

The findings of our analysis mirror those presented in Oster (2008). Oster examines the effect of a continuous increase in healthcare supply measured by health camps on gender inequality in immunisation in India, and finds that at initial levels of the supply increase inequality worsens. As supply continues to increase the inequality eventually dissipates. In our case, a permanent increase in availability of vaccines via the ICDS programme represents a long term, invariant shock in supply. However the household response to the supply shock over time is identical to the response found by Oster to an increase in supply itself. Both sets of results suggest that households respond to initial and uncertain increases in healthcare supply by insuring their sons against illness first, as boys are seen to be more valuable than girls. Daughters are then later vaccinated when supply increases further or when the initial increase is seen to be more than just temporary.

Oster (2006) argues that gender differences in immunisation are responsible for upto be- 
tween 20 to 30 percent of the childhood mortality difference between boys and girls. Indeed it is possible that gender discrimination in childhood health inputs are responsible for the missing Indian women in older age groups as calculated in Ray and Anderson (2008). The authors argue that the bulk of these older missing women can be attributed to a gender differential in susceptibility to infectious disease. It is very possible that gender discrimination in childhood immunisations plays a large part in creating this greater vulnerability to disease in adult Indian women. Given the severity of the sex ratio imbalance in India, it is vital that healthcare policy interventions are designed to deal with such gender discrimination. The results from our analysis suggest that a long term, stable supply of immunisations is an effective means of tackling childhood mortality without worsening the sex ratio further. Temporary or sporadic increases in supply however create a potential trade off between these two concerns, as lower childhood mortality may only be achieved at the cost of a more adverse sex ratio in the population.

\section{References}

[1] Census of India 2001. Series-1, India, Provisional Population Totals, Paper-1 of 2001, Registrar General and Census Commissioner, India, 2001.

[2] India Universal Immunisation Programme Review. WHO India, http: //www.whoindia.org/LinkFiles/Routine_Immunization_Acknowledgements_ contents.pdf, 2005.

[3] Economic Survey of India 2006-07. Ministry of Finance, Government of India, 2007.

[4] Siwan Anderson and Debraj Ray. Missing Women: Age and Disease. Mimeo, University of British Columbia, 2008.

[5] Fred Arnold, Minja Kim Choe, and T. K. Roy. Son Preference, the Family-Building Process and Child Mortality in India. Population Studies, 52(3):301-315, 1998.

[6] Fred Arnold, Sunita Kishor, and T.K. Roy. Sex-Selective Abortions in India. Population and Development Review, 28(4):759-785, 2002.

[7] World Bank. Engendering Development. Technical report, World Bank, 2001.

[8] Pranab K. Bardhan. On Life and Death Questions. Economic and Political Weekly, 9(32/34):1293-1304, August 1974. 
[9] Jere R. Behrman. Intrahousehold Allocation of Nutrients in Rural India: Are Boys Favoured? Do Parents Exhibit Inequality Aversion? Oxford Economic Papers, 40:32$54,1988$.

[10] John C. Caldwell, P. H. Reddy, and Pat Caldwell. The Causes of Demographic Change: Experimental Research in South India. University of Wisconsin Press, Madison, 1989.

[11] Shelley Clark. Son Preference and Sex Composition of Children: Evidence from India. Demography, 37(1):95-108, 2000.

[12] Narayan Das. Sex Preference and Fertility Behaviour: A Study of Recent Indian Data. Demography, 24(4):517-530, 1987.

[13] Monica Das Gupta. Selective Discrimination Against Female Children in Rural Punjab, India. Population and Development Review, 13(1):77-100, 1987.

[14] Partha Dasgupta. An Enquiry into Well-Being and Destitution. Oxford: Clarendon Press, 1993.

[15] Anil B. Deolalikar. Attaining the Millenium Development Goals in India. Washington, D.C.: The World Bank, Human Development Unit, South Asia Region (mimeo), 2004.

[16] Arunachalam Dharmalingam. The Social Context of Family Size Preferences and Fertility Behaviour in a South Indian Village. Genus, 52:83-103, 1996.

[17] Tim Dyson and Mick Moore. On Kinship Structure, Female Autonomy and Demographic Behaviour in India. Population and Development Review, 9(1):35-60, 1983.

[18] Caren Grown, Geeta Rao Gupta, and Rohini Pande. Taking Action to Improve Women's Health through Gender Equality and Women's Empowerment. The Lancet, 365:541-543, 2005.

[19] Sunita Kishor. Gender Differentials in Child Mortality: A Review of the Evidence. In Monica Das Gupta, Lincoln C. Chen, and T. N. Krishnan, editors, Women's Health in India: Risk and Vulnerability, pages 19-54. Oxford University Press, Bombay, 1995.

[20] N. Krishnaji. Poverty and Sex Ratio: Some Data and Speculations. Economic and Political Weekly, June 1987. 
[21] Michael Lokshin, Monica Das Gupta, Michele Gragnolati, and Oleksiy Ivaschenko. Improving Child Nutrition? The Integrated Child Development Services in India. Development and Change, 36(4):613-640, 2005.

[22] A. Marcoux. Sex Differentials in Undernutrition: A Look at Survey Evidence. Population and Development Review, 28(2):275-284, 2002.

[23] Barbera Miller. On Poverty, Child Survival, and Gender: Models and Misperceptions. Third World Planning Review, 15(3):iii-viii, 1993.

[24] Vinad Mishra, T.K. Roy, and Robert Retherford. Sex Differentials in Childhood Feeding, Health Care, and Nutritional Status in India. Population and Development Review, 30(2):269-295, 2004.

[25] Mamta Murthi, Anne-Catherine Guio, and Jean Dreze. Mortality, Fertility, and Gender Bias in India: A District-Level Analysis. Population and Development Review, 21(4):745-782, 1995.

[26] Emily Oster. Proximate Causes of Population Gender Imbalance in India. Mimeo, University of Chicago, 2006.

[27] Emily Oster. Does Increased Access Increase Equality? Gender and Child Health Investments in India. Working Paper 12743, National Bureau of Economic Research, 2008.

[28] Rohini Pande. Selective Gender Differences in Childhood Nutrition and Immunization in Rural India: The Role of Siblings. Demography, 40(3):395-418, 2003.

[29] Elaine Rose. Consumption Smoothing and Excess Female Mortality in Rural India. The Review of Economics and Statistics, 81(1):41-49, 1999.

[30] Mark R. Rosenzweig and T. Paul Schultz. Market Opportunities, Genetic Endowments, and Intrafamily Resource Distribution: Child Survival in Rural India. American Economic Review, 72(4):803-815, 1982.

[31] A. Sen and S. Sengupta. Malnutrition of Rural Children and the Sex Bias. Economic and Political Weekly, (Annual Number 18):855-864, May 1983.

[32] Amartya Sen. Missing Women. New York Review of Books, December 201990. 
Figure 1: New Villages Included in ICDS Programme Per Year (1975-2006)

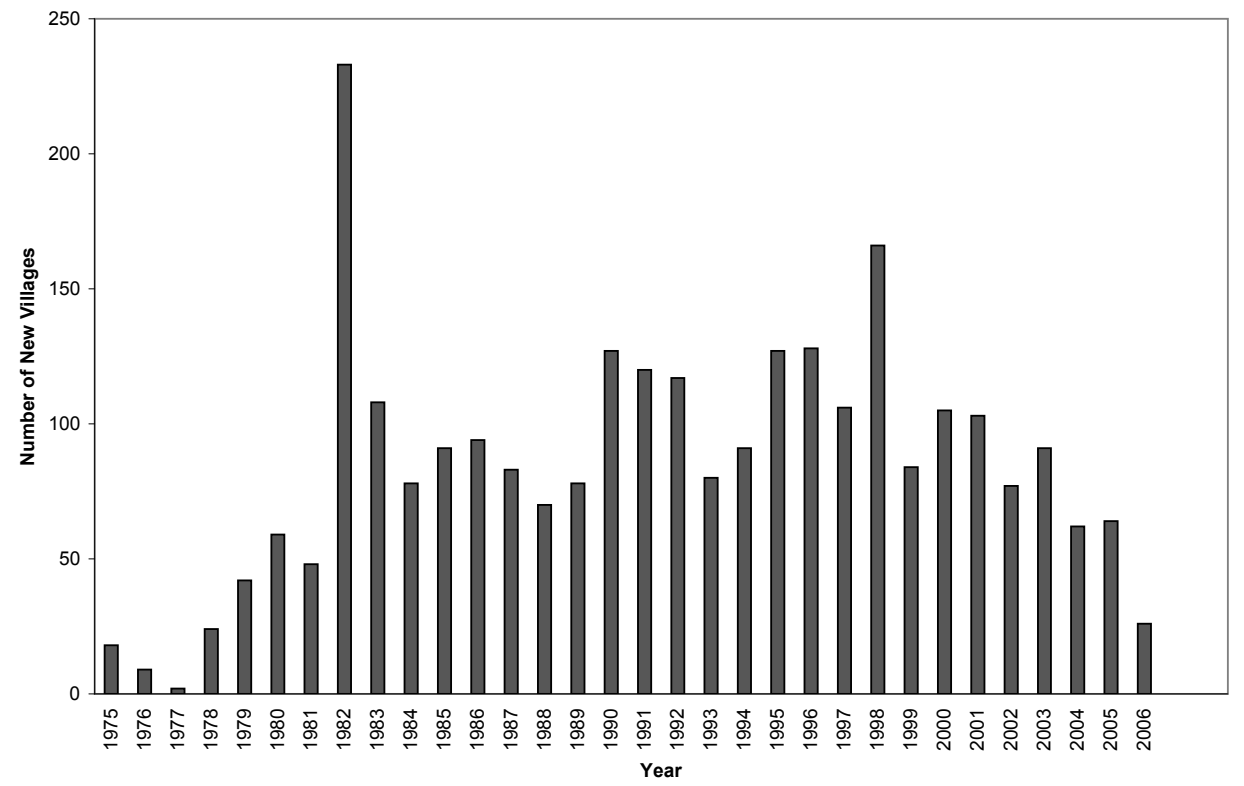

Notes: Figures presented for sample trimmed by marriage and birth order

Figure 2: Fraction of Children by Treatment Status and Propensity Score

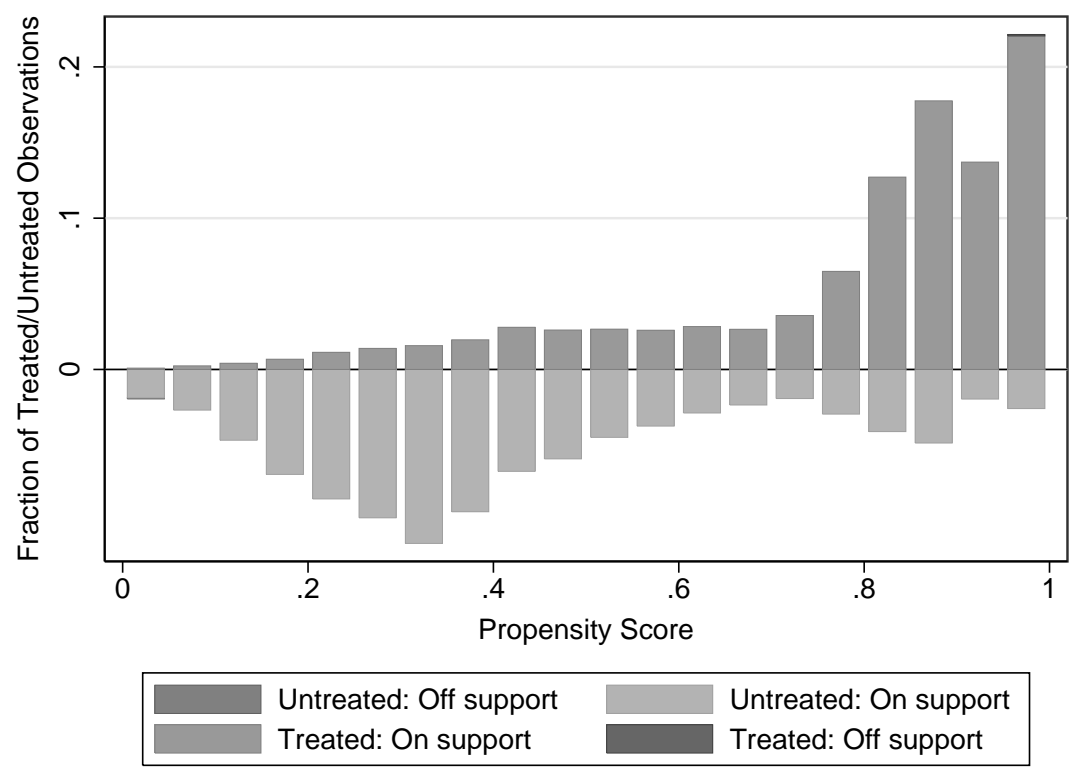

Notes: Figures presented for sample used in regression analysis. 
Table 1: Female-Male Sex Ratio and Per Capita Net Domestic Product

\begin{tabular}{|c|c|c|}
\hline State/Union Territory & Female-Male Sex Ratio (2001) & Per Capita NDP (2003-04) \\
\hline Delhi & 821 & 49,494 \\
\hline Haryana & 861 & 29,504 \\
\hline Punjab & 874 & 28,607 \\
\hline Sikkim & 875 & 22,062 \\
\hline Uttar Pradesh & 898 & 10,637 \\
\hline Jammu and Kashmir & 900 & 15,318 \\
\hline Arunachal Pradesh & 901 & 19,029 \\
\hline Nagaland & 909 & - \\
\hline Madhya Pradesh & 920 & 13,722 \\
\hline Bihar & 921 & 5,362 \\
\hline Gujarat & 921 & 26,672 \\
\hline Rajasthan & 922 & 15,738 \\
\hline Maharashtra & 922 & 28,848 \\
\hline Assam & 932 & 12,821 \\
\hline West Bengal & 934 & 20,548 \\
\hline Mizoram & 938 & - \\
\hline Jharkhand & 941 & 11,999 \\
\hline Tripura & 950 & 20,357 \\
\hline Goa & 960 & 57,369 \\
\hline Uttaranchal & 964 & 16,982 \\
\hline Karnataka & 964 & 21,238 \\
\hline Himachal Pradesh & 970 & 25,059 \\
\hline Orissa & 972 & 12,645 \\
\hline Meghalaya & 975 & 18,135 \\
\hline Manipur & 978 & 13,732 \\
\hline Andhra Pradesh & 978 & 21,372 \\
\hline Tamil Nadu & 986 & 23,358 \\
\hline Chhatisgarh & 990 & 14,963 \\
\hline Kerala & 1,058 & 24,492 \\
\hline
\end{tabular}

Notes: Figures are reported for states in our sample. Female-Male Sex Ratio is reported as the number of females per 1000 males. State per capita NDP reported in rupees at 2003-04 prices. Sex ratios obtained from the Census of India, 2001. State per capita net domestic product obtained from Economic Survey of India, 2006-07. 
Table 2: Mean Difference Tests of Vaccinations By Gender

\begin{tabular}{ccccccc}
\hline Birth Year & Boys & Girls & Difference & SE & Fraction of Girls & Frequency \\
\hline 2001 & 6.29 & 6.08 & $0.21^{* *}$ & 0.076 & 0.473 & 6,575 \\
2002 & 6.28 & 6.18 & 0.10 & 0.064 & 0.484 & 9,414 \\
2003 & 6.37 & 6.24 & $0.13^{*}$ & 0.062 & 0.471 & 9,578 \\
2004 & 6.51 & 6.39 & 0.12 & 0.062 & 0.478 & 9,294 \\
2005 & 5.57 & 5.27 & $0.30^{* *}$ & 0.062 & 0.483 & 9,656 \\
2006 & 2.54 & 2.52 & 0.02 & 0.102 & 0.495 & 2,362 \\
\hline
\end{tabular}

Notes: Means are reported for the sample trimmed by marriage and birth order. The nine vaccinations covered are the BCG vaccine, Measles vaccine, four rounds of the Polio vaccine, and three rounds of the Diphtheria (DPT) vaccine. ${ }^{* *}$ Significant at $1 \%$; Significant at $5 \%$.

Table 3: Proportions Difference Tests of Full Vaccination By Gender

\begin{tabular}{ccccccc}
\hline Birth Year & Boys & Girls & Difference & SE & Fraction of Girls & Frequency \\
\hline 2001 & 0.293 & 0.277 & .016 & 0.011 & 0.473 & 6,575 \\
2002 & 0.308 & 0.295 & 0.012 & 0.009 & 0.484 & 9,414 \\
2003 & 0.324 & 0.306 & 0.017 & 0.009 & 0.471 & 9,578 \\
2004 & 0.351 & 0.327 & $0.023^{*}$ & 0.009 & 0.478 & 9,294 \\
2005 & 0.171 & 0.152 & $0.019^{* *}$ & 0.007 & 0.483 & 9,656 \\
2006 & 0.001 & 0.002 & -0.000 & 0.001 & 0.495 & 2,362 \\
\hline
\end{tabular}

Notes: Proportions are reported for the sample trimmed by marriage and birth order. The nine vaccinations covered are the BCG vaccine, Measles vaccine, four rounds of the Polio vaccine, and three rounds of the Diphtheria (DPT) vaccine. ${ }^{* *}$ Significant at $1 \%$; Significant at $5 \%$. 
Table 4: India DHS 2005-06 - Coverage of ICDS Programme

\begin{tabular}{lccc}
\hline & Villages & Households & Children \\
\hline Covered & 1,999 & 18,574 & 26,251 \\
Not Covered & 1,057 & 8,921 & 12,184 \\
\hline Total & 3,056 & 27,495 & 38,435 \\
\hline ICDS 0-5 Years & 423 & 4,151 & 5,916 \\
ICDS 6-10 Years & 589 & 5,624 & 8,027 \\
ICDS 11-15 Years & 535 & 4,876 & 6,871 \\
ICDS 16-20 Years & 452 & 3,923 & 5,437 \\
\hline Total & 1,999 & 18,574 & 26,251 \\
\hline
\end{tabular}

Notes: Figures are reported for the trimmed sample used for regression analysis. Years of coverage are reported conditional on being covered by an ICDS centre.

Table 5: India DHS 2005-06 - Descriptive Statistics

\begin{tabular}{lcccc}
\hline & Mean & Standard Deviation & Minimum & Maximum \\
\hline Mother's Educational Attainment & 1.80 & - & 0 & 5 \\
Mother's Current Age & 26.14 & 4.91 & 15 & 49 \\
Previous Living Sons & 0.56 & 0.81 & 0 & 5 \\
Previous Living Children & 1.21 & 1.24 & 0 & 5 \\
Birth Order & 2.35 & - & 1 & 6 \\
Mother's Age at Birth & 23.41 & 4.80 & 11 & 47 \\
Smallness at Birth & 2.99 & - & 1 & 5 \\
Preceding Birth Interval & 27.40 & 13.06 & 9 & 159 \\
Succeeding Birth Interval & 32.52 & 18.86 & 9 & 263 \\
\hline
\end{tabular}

Notes: Statistics are reported for the trimmed sample used for regression analysis. Preceding and succeeding birth intervals are reported conditional on there being a preceding or succeeding birth respectively. 
Table 6: Tests of Difference in Means and Proportions by ICDS Coverage

\begin{tabular}{lcccc}
\hline & Non-ICDS & ICDS & Difference & S.E. \\
\hline Mother's Age at Marriage & 18.72 & 17.69 & $1.03^{* *}$ & 0.040 \\
Years of Marriage & 7.43 & 7.78 & $-0.35^{* *}$ & 0.049 \\
Mother's Age at First Birth & 24.49 & 23.88 & $0.61^{* *}$ & 0.062 \\
Child Birth Weight (Grams) & 2835.18 & 2838.34 & -3.16 & 11.32 \\
\hline Rural & 0.256 & 0.768 & $-0.512^{* *}$ & 0.005 \\
Mother Completed Primary Education & 0.613 & 0.485 & $0.128^{* *}$ & 0.005 \\
Mother Completed Secondary Education & 0.226 & 0.092 & $0.134^{* *}$ & 0.004 \\
Muslim & 0.189 & 0.156 & $0.033^{* *}$ & 0.004 \\
Mud/Clay/Earth Floor & 0.181 & 0.376 & $-0.195^{* *}$ & 0.005 \\
Cement Floor & 0.388 & 0.262 & $0.126^{* *}$ & 0.005 \\
Household Owns Refrigerator & 0.316 & 0.128 & $0.188^{* *}$ & 0.004 \\
Household Owns Motorcycle & 0.300 & 0.159 & $0.141^{* *}$ & 0.004 \\
Household Owns Radio & 0.354 & 0.313 & $0.041^{* *}$ & 0.005 \\
Household Owns Television & 0.649 & 0.425 & $0.224^{* *}$ & 0.005 \\
Household Owns Bicycle & 0.444 & 0.501 & $-0.057^{* *}$ & 0.005 \\
Household Owns Car & 0.075 & 0.025 & $0.050^{* *}$ & 0.002 \\
\hline
\end{tabular}

Notes: Means and proportions of mother and household characteristics are reported for the trimmed sample used for regression analysis. ${ }^{* *}$ Significant at $1 \% ;{ }^{*}$ Significant at $5 \%$

Table 7: Government Recommended Immunisation Schedule

\begin{tabular}{cccccl}
\hline Age (Weeks) & BCG & DPT & Polio & Measles & Age Appropriate Coverage \\
\hline Birth & X & & X & & BCG + Polio0 \\
6 & & X & X & & BCG + DPT1 + Polio0-1 \\
10 & & X & X & & BCG + DPT1-2 + Polio0-2 \\
14 & & X & X & & BCG + DPT1-3 + Polio0-3 \\
36 & & & & X & BCG + DPT1-3 + Polio0-3 + Measles \\
\hline
\end{tabular}

Source: Universal Immunisation Programme Division, Department of Family Welfare, Ministry of Health and Family Welfare, India. 
Table 8: Effect of Child Gender on Immunisation

\begin{tabular}{|c|c|c|}
\hline & \multicolumn{2}{|c|}{ Number of Vaccinations } \\
\hline & Village FE & Household FE \\
\hline \multirow{2}{*}{ Girl } & $-0.020 * *$ & $-0.023^{*}$ \\
\hline & $(0.005)$ & $(0.011)$ \\
\hline \multirow{2}{*}{ Previous Living Boys } & $-0.086^{* *}$ & 0.068 \\
\hline & $(0.030)$ & $(0.060)$ \\
\hline \multirow{2}{*}{ Previous Living Boys ${ }^{\wedge} 2$} & $0.015^{*}$ & -0.027 \\
\hline & $(0.007)$ & $(0.016)$ \\
\hline \multirow{2}{*}{ Previous Living Children } & 0.005 & $-1.704^{* *}$ \\
\hline & $(0.015)$ & $(0.060)$ \\
\hline \multirow{2}{*}{ Previous Living Children ^2} & -0.004 & $0.025^{* *}$ \\
\hline & $(0.003)$ & $(0.005)$ \\
\hline \multirow{2}{*}{ At Least One Previous Living Son } & $0.061^{*}$ & -0.054 \\
\hline & $(0.025)$ & $(0.045)$ \\
\hline \multirow{2}{*}{ First Child } & $0.035^{* *}$ & $-0.207^{* *}$ \\
\hline & $(0.013)$ & $(0.025)$ \\
\hline \multirow{2}{*}{ Birth Order } & $-0.019^{*}$ & $1.410^{* *}$ \\
\hline & $(0.008)$ & $(0.065)$ \\
\hline \multirow{2}{*}{ Mother's Age at Birth } & $-0.164^{* *}$ & \\
\hline & $(0.007)$ & \\
\hline \multirow{2}{*}{ Smallness at Birth } & $-0.024^{* *}$ & $-0.026^{* *}$ \\
\hline & $(0.004)$ & $(0.007)$ \\
\hline \multirow{2}{*}{ Preceding Birth Interval } & $0.001^{* *}$ & $-0.003^{* *}$ \\
\hline & $(0.000)$ & $(0.000)$ \\
\hline \multirow{2}{*}{ Succeeding Birth Interval } & $-0.002^{* *}$ & $0.001^{*}$ \\
\hline & $(0.000)$ & $(0.001)$ \\
\hline Observations & 33,046 & 17,686 \\
\hline Number of Villages & 2,953 & \\
\hline Number of Households & - & 8,292 \\
\hline
\end{tabular}

Notes: Robust standard errors clustered at the village level are reported in parentheses. Village fixed-effect specification includes religion, caste, and birth year fixed effects, mother's education and current age, and household wealth indicators as regressors. ${ }^{* *}$ Significant at $1 \% ; *$ Significant at $5 \%$. 
Table 9: Marginal Effects of ICDS Coverage on Gender Bias in Child Immunisation

\begin{tabular}{|c|c|c|c|c|c|c|}
\hline & \multicolumn{6}{|c|}{ Number of Vaccinations } \\
\hline & $(1)$ & $(2)$ & $(3)$ & $(4)$ & $(5)$ & $(6)$ \\
\hline \multirow{2}{*}{ Girl } & -0.003 & 0.001 & -0.005 & -0.003 & 0.001 & -0.004 \\
\hline & $(0.009)$ & $(0.014)$ & $(0.015)$ & $(0.009)$ & $(0.014)$ & $(0.015)$ \\
\hline \multirow{2}{*}{$\mathrm{ICDS} *$ Girl } & $-0.025^{*}$ & $-0.035^{*}$ & -0.022 & -0.008 & 0.007 & -0.002 \\
\hline & $(0.010)$ & $(0.017)$ & $(0.016)$ & $(0.015)$ & $(0.025)$ & $(0.023)$ \\
\hline ICDS * ICDS 0-5 Years * & & & & $-0.039^{*}$ & $-0.078^{* *}$ & $-0.067^{*}$ \\
\hline Girl & & & & $(0.019)$ & $(0.028)$ & $(0.027)$ \\
\hline ICDS * ICDS 6-10 Years * & & & & -0.014 & -0.042 & -0.000 \\
\hline Girl & & & & $(0.016)$ & $(0.025)$ & $(0.025)$ \\
\hline ICDS * ICDS $11-15$ Years * & & & & -0.020 & -0.047 & -0.027 \\
\hline Girl & & & & $(0.018)$ & $(0.028)$ & $(0.026)$ \\
\hline Observations & 33,046 & 17,500 & 18,358 & 33,046 & 17,500 & 18,358 \\
\hline Village Fixed Effects & Yes & Yes & No & Yes & Yes & No \\
\hline Household Fixed Effects & No & No & Yes & No & No & Yes \\
\hline Number of Villages & 2,953 & 2,490 & - & 2,953 & 2,490 & - \\
\hline Number of Households & - & - & 8,608 & - & - & 8,608 \\
\hline
\end{tabular}

Notes: Robust standard errors clustered at the village level are reported in parentheses. Columns (1) and (4) report results for the full sample of children. Columns (2), (3), (5), and (6) report results for the sample of children from households with two or more births during 2001-2006. Additional regressors include mother's educational attainment, mother's current age, education and age interaction terms, birth order and sibling composition variables, religion and caste fixed effects, birth year fixed effects, and child health endowment variables. Household fixed-effect specification does not include mother's age at birth. ${ }^{* *}$ Significant at $1 \% ; *$ Significant at $5 \%$. 
Table 10: ICDS and Gender Bias with State-Gender Interactions

\begin{tabular}{|c|c|c|}
\hline & \multicolumn{2}{|c|}{ Number of Vaccinations } \\
\hline & Village FE & Village FE \\
\hline Girl & $\begin{array}{l}-0.056 \\
(0.041)\end{array}$ & $\begin{array}{l}-0.045 \\
(0.041)\end{array}$ \\
\hline ICDS * Girl & $\begin{array}{c}-0.023^{* *} \\
(0.011)\end{array}$ & $\begin{array}{l}-0.008 \\
(0.016)\end{array}$ \\
\hline ICDS * ICDS 0-5 Years * Girl & & $\begin{array}{c}-0.033^{*} \\
(0.020)\end{array}$ \\
\hline ICDS * ICDS 6-10 Years * Girl & & $\begin{array}{l}-0.010 \\
(0.017)\end{array}$ \\
\hline ICDS * ICDS 11-15 Years * Girl & & $\begin{array}{l}-0.020 \\
(0.018)\end{array}$ \\
\hline State-Gender Interactions & Yes & Yes \\
\hline Observations & 33,046 & 33,046 \\
\hline Number of Villages & 2,953 & 2,953 \\
\hline
\end{tabular}

Notes: Robust standard errors clustered at the village level are reported in parentheses. Additional regressors include mother's educational attainment, mother's current age, education and age interaction terms, birth order and sibling composition variables, religion and caste fixed effects, birth year fixed effects, and child health endowment variables. ${ }^{* * *}$ Significant at $1 \%$; ** Significant at 5\%; ${ }^{*}$ Significant at $10 \%$. 


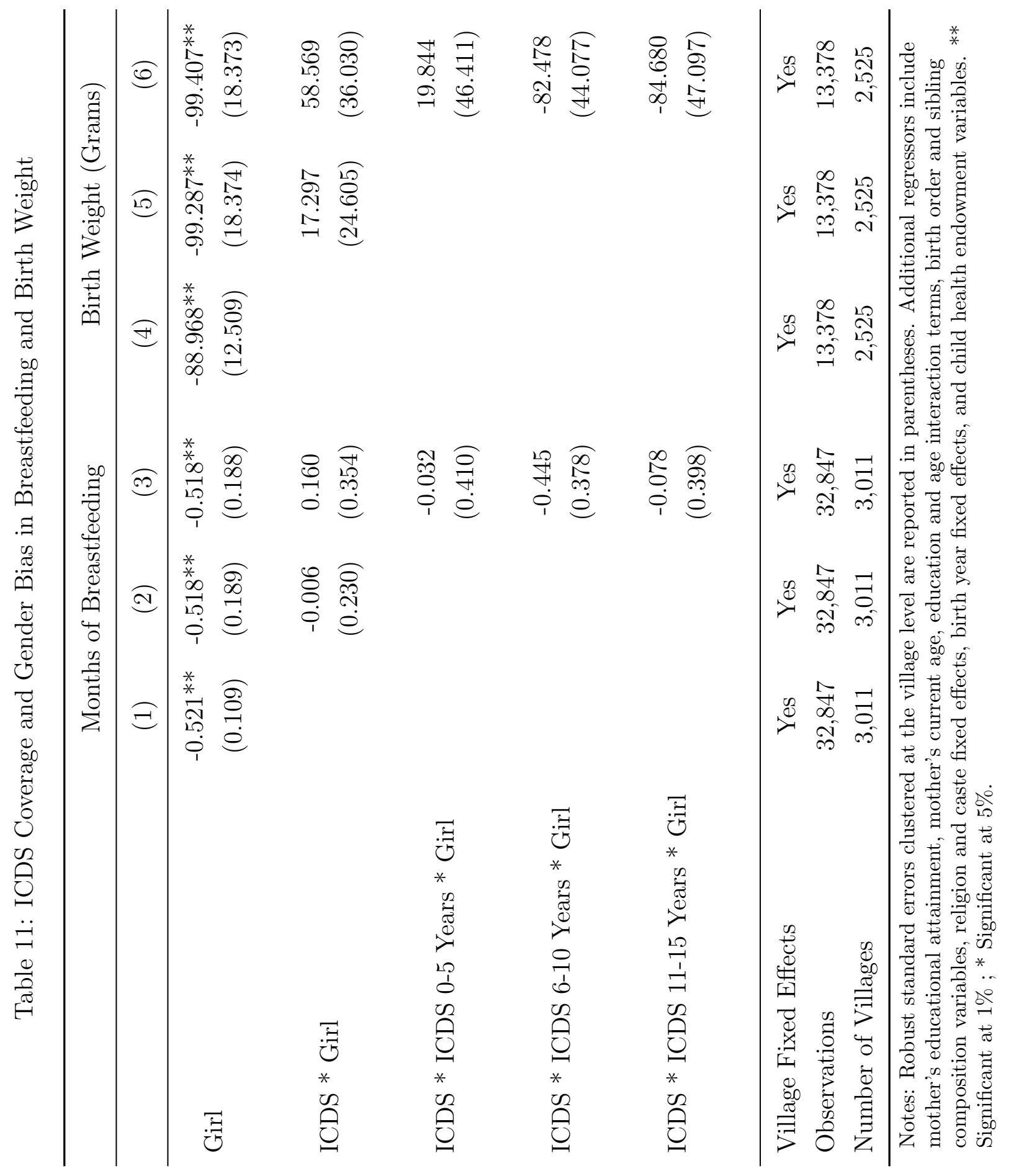


Table 12: 1992-93 State Means and Number of ICDS Centres in 1998-99

\begin{tabular}{|c|c|c|}
\hline & \multicolumn{2}{|c|}{ Number of ICDS Centres } \\
\hline & $(1)$ & $(2)$ \\
\hline Vaccinations & $\begin{array}{l}-372.983^{*} \\
(168.824)\end{array}$ & $\begin{array}{c}-303.417 \\
(1,351.177)\end{array}$ \\
\hline Vaccinations Boy-Girl Difference & $\begin{array}{c}-77.774 \\
(285.318)\end{array}$ & $\begin{array}{c}-22.243 \\
(327.251)\end{array}$ \\
\hline Vaccinations ^2 & & $\begin{array}{c}-56.449 \\
(824.338)\end{array}$ \\
\hline Vaccinations Boy-Girl Difference ^2 & & $\begin{array}{c}752.268 \\
(1,785.270)\end{array}$ \\
\hline Weight-Age Percentile & $\begin{array}{c}-0.138^{* *} \\
(0.044)\end{array}$ & $\begin{array}{l}-0.122 \\
(0.072)\end{array}$ \\
\hline Weight-Age Percentile Boy-Girl Difference & $\begin{array}{c}0.281 \\
(0.279)\end{array}$ & $\begin{array}{c}0.273 \\
(0.369)\end{array}$ \\
\hline Village Distance from Primary & 74.202 & 75.610 \\
\hline School & $(139.893)$ & $(262.553)$ \\
\hline Village Distance from Town & $\begin{array}{l}-2.032 \\
(3.730)\end{array}$ & $\begin{array}{l}-0.720 \\
(7.573)\end{array}$ \\
\hline Village Distance from Tehsil Headquarters & $\begin{array}{l}16.426^{*} \\
(6.240)\end{array}$ & $\begin{array}{c}16.721 \\
(13.290)\end{array}$ \\
\hline Village Distance from Railway Station & $\begin{array}{c}0.457 \\
(0.537)\end{array}$ & $\begin{array}{c}0.438 \\
(0.875)\end{array}$ \\
\hline Village Distance from Paved Road & $\begin{array}{c}10.143 \\
(17.173)\end{array}$ & $\begin{array}{c}8.003 \\
(41.215)\end{array}$ \\
\hline Observations & 24 & 24 \\
\hline R-Squared & 0.93 & 0.94 \\
\hline
\end{tabular}

Notes: Robust standard errors clustered at the state level are reported in parentheses. Additional regressors include the mean village distance from middle and secondary school, mean village distance from the block headquarters, mean village distance from the the nearest bus stop, the probability that a village is electrified, the probability that a village has access to an all-weather road, and the fraction of girls in the sample of children for which vaccination data was collected in 1992-93. ${ }^{* *}$ Significant at $1 \% ; *$ Significant at $5 \%$. 
Table 13: Mean Immunisation Difference Tests by Propensity Score

\begin{tabular}{ccccccc}
\hline Propensity Score & Boys & Girls & Difference & S.E. & Fraction of Girls & Frequency \\
\hline$\geq 0.90$ & 5.99 & 5.98 & 0.008 & 0.159 & 0.477 & 1,570 \\
$\geq 0.85$ & 5.87 & 5.76 & 0.118 & 0.139 & 0.479 & 2,083 \\
$\geq 0.80$ & 5.69 & 5.59 & 0.101 & 0.126 & 0.480 & 2,514 \\
$\geq 0.75$ & 5.61 & 5.54 & 0.068 & 0.119 & 0.478 & 2,825 \\
$\geq 0.70$ & 5.60 & 5.55 & 0.058 & 0.115 & 0.478 & 3,020 \\
\hline
\end{tabular}

Notes: The propensity score for probability of selection into treatment is calculated using one-to-one matching. Tests are performed for children born in 2005 or earlier. Variables used to calculate the score include household wealth indicators, state fixed effects, and religion and caste fixed effects. ${ }^{* *}$ Significant at $1 \% ;{ }^{*}$ Significant at $5 \%$.

Table 14: Proportions Difference Tests of Full Vaccination by Propensity Score

\begin{tabular}{ccccccc}
\hline Propensity Score & Boys & Girls & Difference & S.E. & Fraction of Girls & Frequency \\
\hline$\geq 0.90$ & 0.255 & 0.267 & -0.012 & 0.022 & 0.477 & 1,570 \\
$\geq 0.85$ & 0.236 & 0.227 & 0.008 & 0.018 & 0.479 & 2,083 \\
$\geq 0.80$ & 0.215 & 0.213 & 0.002 & 0.016 & 0.480 & 2,514 \\
$\geq 0.75$ & 0.207 & 0.205 & 0.001 & 0.015 & 0.478 & 2,825 \\
$\geq 0.70$ & 0.209 & 0.206 & 0.002 & 0.014 & 0.478 & 3,020 \\
\hline
\end{tabular}

Notes: The propensity score for probability of selection into treatment is calculated using one-to-one matching. Tests are performed for children born in 2005 or earlier. Variables used to calculate the score include household wealth indicators, state fixed effects, and religion and caste fixed effects. ${ }^{* *}$ Significant at $1 \% ; *$ Significant at $5 \%$. 
Table 15: Gender Bias in Immunisations by ICDS Coverage and Propensity Score

\begin{tabular}{|c|c|c|c|c|c|c|}
\hline & \multicolumn{6}{|c|}{ Number of Vaccinations } \\
\hline & \multicolumn{3}{|c|}{ Non-ICDS } & \multicolumn{3}{|c|}{ ICDS } \\
\hline & $p \geq 0.65$ & $p \geq 0.75$ & $p \geq 0.85$ & $p \geq 0.65$ & $p \geq 0.75$ & $p \geq 0.85$ \\
\hline Girl & $\begin{array}{c}0.002 \\
(0.025)\end{array}$ & $\begin{array}{l}-0.007 \\
(0.027)\end{array}$ & $\begin{array}{l}-0.007 \\
(0.041)\end{array}$ & $\begin{array}{c}-0.033^{* *} \\
(0.007)\end{array}$ & $\begin{array}{c}-0.032^{* *} \\
(0.008)\end{array}$ & $\begin{array}{c}-0.026^{* *} \\
(0.009)\end{array}$ \\
\hline Previous Living Boys & $\begin{array}{l}-0.034 \\
(0.100)\end{array}$ & $\begin{array}{l}-0.163 \\
(0.114)\end{array}$ & $\begin{array}{l}-0.075 \\
(0.190)\end{array}$ & $\begin{array}{c}-0.087^{*} \\
(0.038)\end{array}$ & $\begin{array}{c}-0.090^{*} \\
(0.038)\end{array}$ & $\begin{array}{l}-0.092^{*} \\
(0.046)\end{array}$ \\
\hline Previous Living Boys ^2 & $\begin{array}{c}0.015 \\
(0.024)\end{array}$ & $\begin{array}{c}0.046 \\
(0.028)\end{array}$ & $\begin{array}{c}0.030 \\
(0.045)\end{array}$ & $\begin{array}{c}0.015 \\
(0.009)\end{array}$ & $\begin{array}{c}0.017 \\
(0.009)\end{array}$ & $\begin{array}{c}0.020 \\
(0.011)\end{array}$ \\
\hline Previous Living Children & $\begin{array}{l}-0.025 \\
(0.059)\end{array}$ & $\begin{array}{c}0.024 \\
(0.066)\end{array}$ & $\begin{array}{l}-0.030 \\
(0.097)\end{array}$ & $\begin{array}{c}0.008 \\
(0.020)\end{array}$ & $\begin{array}{c}0.003 \\
(0.020)\end{array}$ & $\begin{array}{c}0.009 \\
(0.023)\end{array}$ \\
\hline Previous Living Children ^2 & $\begin{array}{l}-0.001 \\
(0.010)\end{array}$ & $\begin{array}{l}-0.009 \\
(0.011)\end{array}$ & $\begin{array}{l}-0.003 \\
(0.017)\end{array}$ & $\begin{array}{l}-0.003 \\
(0.004)\end{array}$ & $\begin{array}{l}-0.004 \\
(0.004)\end{array}$ & $\begin{array}{l}-0.006 \\
(0.005)\end{array}$ \\
\hline At Least One Previous Living Son & $\begin{array}{l}-0.030 \\
(0.084)\end{array}$ & $\begin{array}{c}0.069 \\
(0.098)\end{array}$ & $\begin{array}{c}0.044 \\
(0.157)\end{array}$ & $\begin{array}{l}0.072^{*} \\
(0.032)\end{array}$ & $\begin{array}{l}0.068^{*} \\
(0.032)\end{array}$ & $\begin{array}{c}0.052 \\
(0.038)\end{array}$ \\
\hline First Child & $\begin{array}{l}-0.015 \\
(0.054)\end{array}$ & $\begin{array}{c}0.044 \\
(0.059)\end{array}$ & $\begin{array}{c}0.020 \\
(0.079)\end{array}$ & $\begin{array}{l}0.046^{*} \\
(0.019)\end{array}$ & $\begin{array}{l}0.046^{*} \\
(0.019)\end{array}$ & $\begin{array}{c}0.033 \\
(0.022)\end{array}$ \\
\hline Birth Order & $\begin{array}{l}-0.006 \\
(0.026)\end{array}$ & $\begin{array}{c}0.006 \\
(0.030)\end{array}$ & $\begin{array}{c}0.031 \\
(0.047)\end{array}$ & $\begin{array}{l}-0.021 \\
(0.011)\end{array}$ & $\begin{array}{l}-0.016 \\
(0.011)\end{array}$ & $\begin{array}{l}-0.012 \\
(0.013)\end{array}$ \\
\hline Mother's Educational Attainment & $\begin{array}{c}0.158^{* *} \\
(0.040)\end{array}$ & $\begin{array}{c}0.150^{* *} \\
(0.048)\end{array}$ & $\begin{array}{c}0.178^{*} \\
(0.073)\end{array}$ & $\begin{array}{c}0.063^{* *} \\
(0.014)\end{array}$ & $\begin{array}{c}0.058^{* *} \\
(0.015)\end{array}$ & $\begin{array}{c}0.060^{* *} \\
(0.018)\end{array}$ \\
\hline Mother's Current Age & $\begin{array}{c}0.201^{* *} \\
(0.021)\end{array}$ & $\begin{array}{c}0.195^{* *} \\
(0.024)\end{array}$ & $\begin{array}{c}0.206^{* *} \\
(0.037)\end{array}$ & $\begin{array}{c}0.202^{* *} \\
(0.008)\end{array}$ & $\begin{array}{c}0.205^{* *} \\
(0.008)\end{array}$ & $\begin{array}{c}0.199 * * \\
(0.009)\end{array}$ \\
\hline Mother's Age at Birth & $\begin{array}{c}-0.182^{* *} \\
(0.031)\end{array}$ & $\begin{array}{c}-0.169^{* *} \\
(0.037)\end{array}$ & $\begin{array}{c}-0.240^{* *} \\
(0.049)\end{array}$ & $\begin{array}{c}-0.159^{* *} \\
(0.010)\end{array}$ & $\begin{array}{c}-0.161^{* *} \\
(0.011)\end{array}$ & $\begin{array}{c}-0.155^{* *} \\
(0.012)\end{array}$ \\
\hline Smallness at Birth & $\begin{array}{l}-0.023 \\
(0.015)\end{array}$ & $\begin{array}{c}-0.024 \\
(0.018)\end{array}$ & $\begin{array}{c}-0.064^{* *} \\
(0.025)\end{array}$ & $\begin{array}{c}-0.016^{* *} \\
(0.005)\end{array}$ & $\begin{array}{c}-0.016^{* *} \\
(0.005)\end{array}$ & $\begin{array}{c}-0.018^{* *} \\
(0.006)\end{array}$ \\
\hline Village Fixed Effects & Yes & Yes & Yes & Yes & Yes & Yes \\
\hline Observations & 2,185 & 1,741 & 975 & 17,762 & 16,390 & 12,073 \\
\hline Number of Villages & 231 & 170 & 128 & 1,558 & 1,457 & 1,261 \\
\hline
\end{tabular}

Notes: Robust standard errors clustered at the village level are reported in parentheses. The propensity score $p$ for probability of selection into treatment is calculated using one-to-one matching. Additional regressors include religion, caste, and birth year fixed effects, preceding and succeeding birth intervals, and household wealth indicators. ${ }^{* *}$ Significant at $1 \% ; *$ Significant at $5 \%$. 
Table 16: Household Wealth and Gender Bias

\begin{tabular}{|c|c|c|c|c|c|c|}
\hline & \multicolumn{4}{|c|}{ Number of Vaccinations } & \multirow[b]{2}{*}{ (5) } & \multirow[b]{2}{*}{ (6) } \\
\hline & (1) & $(2)$ & $(3)$ & $(4)$ & & \\
\hline Girl & $\begin{array}{c}-0.020^{* *} \\
(0.005)\end{array}$ & $\begin{array}{l}-0.003 \\
(0.009)\end{array}$ & $\begin{array}{c}-0.020^{* *} \\
(0.005)\end{array}$ & $\begin{array}{l}-0.003 \\
(0.009)\end{array}$ & $\begin{array}{c}-0.021^{* *} \\
(0.009)\end{array}$ & $\begin{array}{l}-0.004 \\
(0.008)\end{array}$ \\
\hline ICDS * Girl & & $\begin{array}{l}-0.025^{*} \\
(0.010)\end{array}$ & & $\begin{array}{c}-0.026^{*} \\
(0.010)\end{array}$ & & $\begin{array}{r}-0.026^{*} \\
(0.011)\end{array}$ \\
\hline Household has Electricity & $\begin{array}{c}0.045^{* *} \\
(0.013)\end{array}$ & $\begin{array}{c}0.045^{* *} \\
(0.013)\end{array}$ & $\begin{array}{c}0.035^{* *} \\
(0.013)\end{array}$ & $\begin{array}{c}0.035 * * \\
(0.013)\end{array}$ & $\begin{array}{l}0.028^{*} \\
(0.013)\end{array}$ & $\begin{array}{l}0.028^{*} \\
(0.013)\end{array}$ \\
\hline Household owns Radio & $\begin{array}{l}0.013^{*} \\
(0.006)\end{array}$ & $\begin{array}{c}0.013^{*} \\
(0.006)\end{array}$ & $\begin{array}{c}0.008 \\
(0.006)\end{array}$ & $\begin{array}{c}0.008 \\
(0.006)\end{array}$ & $\begin{array}{c}0.003 \\
(0.006)\end{array}$ & $\begin{array}{c}0.003 \\
(0.006)\end{array}$ \\
\hline Household owns Television & $\begin{array}{c}0.036^{* *} \\
(0.008)\end{array}$ & $\begin{array}{c}0.036^{* *} \\
(0.008)\end{array}$ & $\begin{array}{c}0.022^{* *} \\
(0.008)\end{array}$ & $\begin{array}{c}0.022^{* *} \\
(0.008)\end{array}$ & $\begin{array}{c}0.013 \\
(0.009)\end{array}$ & $\begin{array}{c}0.013 \\
(0.009)\end{array}$ \\
\hline Household owns Bicycle & $\begin{array}{c}0.019^{* *} \\
(0.007)\end{array}$ & $\begin{array}{c}0.019 * * \\
(0.007)\end{array}$ & $\begin{array}{l}0.015^{*} \\
(0.007)\end{array}$ & $\begin{array}{l}0.015^{*} \\
(0.007)\end{array}$ & $\begin{array}{c}0.013 \\
(0.007)\end{array}$ & $\begin{array}{c}0.013 \\
(0.007)\end{array}$ \\
\hline Household owns Motorcycle & $\begin{array}{l}0.015^{*} \\
(0.008)\end{array}$ & $\begin{array}{l}0.015^{*} \\
(0.008)\end{array}$ & $\begin{array}{c}0.005 \\
(0.008)\end{array}$ & $\begin{array}{c}0.005 \\
(0.008)\end{array}$ & $\begin{array}{c}0.003 \\
(0.008)\end{array}$ & $\begin{array}{c}0.003 \\
(0.008)\end{array}$ \\
\hline Household owns Refrigerator & $\begin{array}{c}0.012 \\
(0.009)\end{array}$ & $\begin{array}{c}0.012 \\
(0.009)\end{array}$ & $\begin{array}{c}0.007 \\
(0.009)\end{array}$ & $\begin{array}{c}0.007 \\
(0.009)\end{array}$ & $\begin{array}{c}0.007 \\
(0.009)\end{array}$ & $\begin{array}{c}0.007 \\
(0.009)\end{array}$ \\
\hline Household owns Car & $\begin{array}{l}-0.004 \\
(0.011)\end{array}$ & $\begin{array}{l}-0.004 \\
(0.011)\end{array}$ & $\begin{array}{l}-0.005 \\
(0.011)\end{array}$ & $\begin{array}{l}-0.005 \\
(0.011)\end{array}$ & $\begin{array}{l}-0.005 \\
(0.011)\end{array}$ & $\begin{array}{l}-0.005 \\
(0.011)\end{array}$ \\
\hline Household owns Pressure Cooker & & & $\begin{array}{c}0.048^{* *} \\
(0.009)\end{array}$ & $\begin{array}{c}0.048^{* *} \\
(0.009)\end{array}$ & $\begin{array}{c}0.043^{* *} \\
(0.010)\end{array}$ & $\begin{array}{c}0.043^{* *} \\
(0.010)\end{array}$ \\
\hline Household owns Chair & & & $\begin{array}{c}0.038^{* *} \\
(0.009)\end{array}$ & $\begin{array}{c}0.038^{* *} \\
(0.009)\end{array}$ & $\begin{array}{c}0.034^{* *} \\
(0.009)\end{array}$ & $\begin{array}{c}0.034^{* *} \\
(0.009)\end{array}$ \\
\hline Household owns Cot/Bed & & & $\begin{array}{l}0.027^{*} \\
(0.012)\end{array}$ & $\begin{array}{l}0.027^{*} \\
(0.012)\end{array}$ & $\begin{array}{c}0.020 \\
(0.013)\end{array}$ & $\begin{array}{c}0.020 \\
(0.013)\end{array}$ \\
\hline Household owns Tractor & & & $\begin{array}{l}0.048^{*} \\
(0.021)\end{array}$ & $\begin{array}{l}0.048^{*} \\
(0.021)\end{array}$ & $\begin{array}{l}0.045^{*} \\
(0.021)\end{array}$ & $\begin{array}{l}0.045^{*} \\
(0.021)\end{array}$ \\
\hline Household Standard of Living Index & & & & & $\begin{array}{l}0.018^{*} \\
(0.008)\end{array}$ & $\begin{array}{l}0.018^{*} \\
(0.008)\end{array}$ \\
\hline Observations & 33,046 & 33,046 & 33,025 & 33,025 & 32,380 & 32,380 \\
\hline Village Fixed Effects & Yes & Yes & Yes & Yes & Yes & Yes \\
\hline Floor and Roof Material Indicators & Yes & Yes & Yes & Yes & Yes & Yes \\
\hline Toilet Type Indicators & Yes & Yes & Yes & Yes & Yes & Yes \\
\hline Number of Villages & 2,953 & 2,953 & 2,953 & 2,953 & 2,943 & 2,943 \\
\hline
\end{tabular}

Notes: Robust standard errors clustered at the village level are reported in parentheses. Additional regressors include mother's educational attainment, mother's current age, education and age interaction terms, birth order and sibling composition variables, religion and caste fixed effects, birth year fixed effects, and child health endowment variables. ${ }^{* *}$ Significant at $1 \% ; *$ Significant at $5 \%$. 
Table 17: ICDS Duration Effect on Treated Population

\begin{tabular}{|c|c|c|}
\hline & \multicolumn{2}{|c|}{ Number of Vaccinations } \\
\hline & $(1)$ & $(2)$ \\
\hline ICDS 0-5 Years & $\begin{array}{c}-0.157^{*} \\
(0.063)\end{array}$ & $\begin{array}{l}-0.053 \\
(0.040)\end{array}$ \\
\hline ICDS 6-10 Years & $\begin{array}{l}-0.006 \\
(0.041)\end{array}$ & $\begin{array}{c}0.007 \\
(0.041)\end{array}$ \\
\hline ICDS 11-15 Years & $\begin{array}{l}-0.022 \\
(0.043)\end{array}$ & $\begin{array}{c}-0.011 \\
(0.043)\end{array}$ \\
\hline ICDS 0-5 Years * Girl & & $\begin{array}{c}-0.049 * * \\
(0.013)\end{array}$ \\
\hline ICDS 6-10 Years * Girl & & $\begin{array}{c}-0.028^{*} \\
(0.011)\end{array}$ \\
\hline ICDS 11-15 Years * Girl & & $\begin{array}{l}-0.023 \\
(0.013)\end{array}$ \\
\hline State Fixed Effects & Yes & Yes \\
\hline Observations & 22,425 & 22,425 \\
\hline Number of Villages & 1,976 & 1,976 \\
\hline
\end{tabular}

Notes: Robust standard errors clustered at the village level are reported in parentheses. Additional regressors include mother's educational attainment, mother's current age, education and age interaction terms, birth order and sibling composition variables, religion and caste fixed effects, birth year fixed effects, household wealth indicators, and child health endowment variables. ${ }^{* *}$ Significant at $1 \% ;{ }^{*}$ Significant at $5 \%$. 